\title{
Experimental and numerical rolling contact fatigue study on the 32CrMoV13 steel
}

\author{
L. COELHO ${ }^{1}$, A. DIAS ${ }^{2}$, H. P. LIEURADE ${ }^{3}$ and H. MAITOURNAM ${ }^{4}$ \\ ${ }^{1}$ Escola Superior de Ciências e Tecnologia, Universidade Católica Portuguesa, Rua Dr. Mendes Pinheiro, 24, 3080-032 Figueira da Foz, Portugal, \\ ${ }^{2}$ Departamento de Engenharia Mecânica, Pólo II da Universidade de Coimbra. Pinhal de Marrocos, 3030-201 Coimbra, Portugal, ${ }^{3}$ Centre Technique \\ des Industries Mécaniques, CETIM, 52, Avenue Félix-Louat BP 80067, 60304 Senlis Cedex, France, ${ }^{4}$ Laboratoire de Mécanique des Solides, CNRS \\ URA 317, École Polytechnique, 91128 Palaiseau Cedex, France
}

Received in final form 9 March 2004

\begin{abstract}
The aim of this work is to study pure rolling contact fatigue in $32 \mathrm{CrMoV} 13$ quenching and tempering steel. The study involves both experimental and numerical work. The influence of the roughness and the residual stresses on the mechanisms and zones of cracking were studied. The results show a rapid reduction in roughness during the first minute of test but even so there will be specimen deterioration. The residual stress profile after rolling contact tests have high compression values in the surface and at a depth of approximately $240 \mu \mathrm{m}$, which is related with the Hertzian maximal shear stress. The numerical simulation of the Hertzian loading was used both to determine the elastic shakedown of the material and to apply a high-cycle multiaxial fatigue criterion. The threedimensional finite element analysis used in the numerical calculation includes elastic-linear kinematic hardening plastic material and allows the introduction of an initial residual stress state. Taking into account the elastoplastic load induced by the Hertz pressure, low-cycle fatigue tests were used to characterize the mechanical properties of the material. In order to validate the numerical simulation, the results of the calculation after elastic shakedown were compared with the values measured by $\mathrm{X}$-ray diffraction after rolling contact tests. The results showed a reasonable agreement between calculated and measured stresses. The Dang Van high-cycle multiaxial fatigue criterion showed a good relationship with the experimental findings.
\end{abstract}

Keywords fatigue contact; multiaxial fatigue criterion; numerical simulation; residual stress; roughness.

\section{INTRODUCTION}

The typical deterioration mode of rolling contact fatigue (RCF) is known as 'spalling' and its shape is associated with the origin of the initiating crack. ${ }^{1-3}$ A rectangularshaped spall means a deep-initiated crack while a fanshaped spalling means a surface-initiated crack.

Continuing improvements in steel processing have led to fewer inclusions and an upper level of cleanness in the subsurface. As a consequence, the mechanical properties and condition of the surface are decisive $e^{4,5}$ and roughness investigations have been increased over the past few years. Ichimaru et al., ${ }^{6}$ have related the fact that contact fatigue is a process of repeated plastic deformation due to

Correspondence: L. Coelho. E-mail: coelho@crb.ucp.pt the interaction of asperities. Cheng et al., ${ }^{7}$ noted that, in pure rolling, longitudinal cracks were first initiated from the finishing grooves on the specimen surface and can be in the central part or formed towards the two sides of the wear track, depending on elastohydrodynamic lubrication condition. Soda and Yamamoto ${ }^{8}$ concluded that the roughness of the harder mating roller has a marked influence on the fatigue life: the smoother the mating roller, the longer the life.

The residual stresses are also very important. Many authors observed that the maximum values of induced compressive residual stresses occurred at a depth that corresponds to the maximum shear stress depth below the running track surface. ${ }^{9,10}$

The numerical simulation of contact fatigue has been the subject of recent development. Initially, Bhargava et al. ${ }^{11}$ 
Table 1 Chemical composition of the $32 \mathrm{CrMoV} 13$ quenching and tempered steel

\begin{tabular}{llllllllllll}
\hline Element & $\mathrm{C}$ & $\mathrm{Si}$ & $\mathrm{Mn}$ & $\mathrm{S}$ & $\mathrm{P}$ & $\mathrm{Ni}$ & $\mathrm{Cr}$ & $\mathrm{Mo}$ & $\mathrm{V}$ \\
\hline$\%$ & 0.32 & 0.35 & 0.52 & $<0.003$ & $<0.013$ & 0.14 & 3.0 & 0.83 & 0.28 \\
\hline
\end{tabular}

used a two-dimensional (plane strain) elastoplastic finite element model with an elastic-perfectly plastic idealization of the cyclic plastic behaviour. Later on, Hahn et al. ${ }^{12}$ and Batista et al..$^{13}$ developed an elastic-linear-kinematic hardening-plastic behaviour model. In 1991, Kulkarni et al. ${ }^{14}$ extended the study to three-dimensional rolling contact with the same material behaviour. However, this kind of approach has the inconvenience of being timeconsuming and cumbersome. To overcome this difficulty, Dang Van and Maitournam developed an approach that allows the elastic shakedown to be achieved within a very short calculation time,${ }^{15}$ by using a reference system that moves with the loads. This means that in this reference frame, the velocities and all the physical quantities are time-independent. The repeated contact is simulated by a series of recurring passes (rotation in this type of specimen) until the steady state is reached.

Firstly, this paper presents an experimental work related to the study of the roughness, residual stresses and cracking mechanisms and zones under pure RCF conditions in heat-treated alloyed steel.

The second part of the work deals with the numerical simulation of the contact fatigue loading, using the Dang Van and Maitournam approach. To validate the numerical simulation, the calculated results were compared with residual stresses measured by $\mathrm{X}$-ray diffraction, before and after pure RCF tests. Subsequently, the Dang Van highcycle multiaxial fatigue criterion was applied to identify the most probable failure zones. ${ }^{16}$

\section{EXPERIMENTAL PROCEDURES}

The material employed in these experiments was $32 \mathrm{Cr}$ MoV13 quenching and tempered steel. Table 1 presents the chemical composition. Austenitizing was performed for $30 \mathrm{~min}$ at $950{ }^{\circ} \mathrm{C}$, followed by quenching in oil and tempering for $4 \mathrm{~h}$ at $635^{\circ} \mathrm{C}$, with cooling in air.

To simulate pure rolling contact, a two-disc type RCFtesting machine with lubrication was used (Fig. 1a). This machine allows contact fatigue tests to be performed between two cylindrical specimens with control of the radial load, the rotation speed, the relative sliding, the contact load, the lubricant and the working temperature. These conditions simulate those found in gears and in bearings. An electrical motor rotates the specimens, through a tim- ing belt drive to the input shaft of a bevel gear box with two output shafts. The specimens are then driven by a double timing belt drive. An independent hydraulic system of a sump (with thermostat and hydraulic pomp) assured the lubrication. The return of the lubricant is by gravity. Electromagnetic sensors of variable reluctance that permanently monitor the surface of each specimen detect spalling. The outputs to an oscilloscope that amplifies the signal and compares them with previously defined limits, allowing the test to be stopped at the first sign of a defect. A simple pneumatic cylinder provides the loading contact, through a load cell and an electronic pressure regulator. This group of components is supported by a structure mounted on dampers.

As illustrated in Fig. 1b, the specimens were $70 \mathrm{~mm}$ in diameter, $7 \mathrm{~mm}$ width and had $40 \mathrm{~mm}$ curvature radius. An $11.7 \mathrm{~m} \mathrm{~s}^{-1}$ circumferential velocity for both discs has been used and the oil temperature was maintained at $56{ }^{\circ} \mathrm{C}$. Hydraulic oil with $46 \mathrm{~mm}^{2} \mathrm{~s}^{-1}, 40^{\circ} \mathrm{C}$ kinematic viscosity and $13.39 \mathrm{GPa}^{-1}$ of viscosity pressure coefficient were applied as a lubricant. ${ }^{17}$

The contact conditions and the results obtained for the minimum oil film thickness, $b_{\min }$, superficial roughness, $R_{\mathrm{a}}$, and lambda ratio, $\Lambda$, are showed in Table 2. The lambda ratio, $\Lambda$, is the relationship between the elastohydrodynamic oil film thickness and the composite surface roughness, ${ }^{18}$

$\Lambda=b / \sigma$,

where $b$ is the minimum oil film thickness and $\sigma$ the composite surface roughness. The oil film thickness was determined by the formula of Hamrock and Dowson. ${ }^{19}$

In order to identify the failure mechanisms, the specimens were inspected with a magnifying glass, and optical and scanning-electron microscopes. The influence of the roughness was tested. The specimens have been polished in the circumferential direction as to obtain the two different levels of surface finish $R_{\mathrm{a}}=0.1 \mu \mathrm{m}(\Lambda>1.5)$ and $0.5 \mu \mathrm{m}(\Lambda<1)$. A cutoff of $0.8 \mathrm{~mm}$ was used for measuring the arithmetic average value of filtered roughness $\left(R_{\mathrm{a}}\right)$ before and after the RCF tests, following the DIN 4768 norm.

Surface and in-depth residual stress were measured, using X-ray diffraction, before and after RCF tests, in three areas along the specimens periphery (disposed of $120^{\circ}$ apart, Fig. 2a and Fig. 3b) and from the centre to the lateral zone of the cylindrical surface, in order to analyse the distribution of values (Fig. 2b). The subsurface residual stress was determined at varying depths below the surface, using an electropolishing technique to remove material. Lattice deformations of the $\{211\}$ diffraction planes of the $\alpha$-Fe phase were measured using $\mathrm{Cr} \mathrm{K}_{\alpha} \mathrm{X}$-ray radiation with vanadium filter in the diffraction beam. The $\mathrm{X}$-ray diffraction peak position was determined by the 




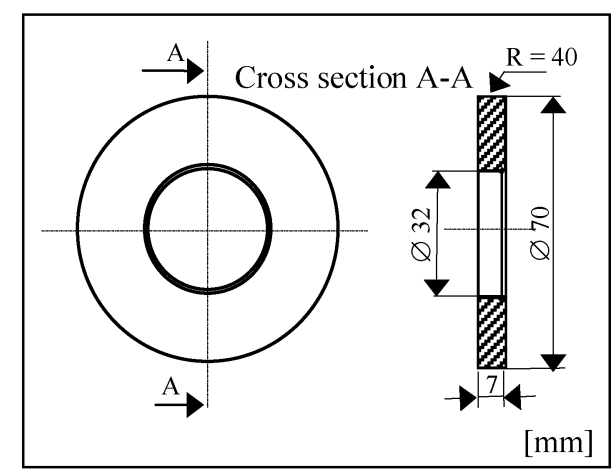

(b)

Fig. 1 (a) RCF testing machine. (b) Roller specimens shape and dimensions.

Table 2 RCF tests. Contact conditions: load, Hertz pressure, contact area, minimum film thickness, roughness and lambda ratio, $\Lambda$

\begin{tabular}{|c|c|c|c|c|c|}
\hline $\begin{array}{l}\text { Load } \\
\text { (N) }\end{array}$ & $\begin{array}{l}\text { Hertz } \\
\text { pressure } \\
(\mathrm{MPa})\end{array}$ & $\begin{array}{l}\text { Contact } \\
\text { area } \\
(\mathrm{mm})\end{array}$ & $\begin{array}{l}\text { Minimum film } \\
\text { thickness, } \\
\mathrm{h}_{\min }(\mu \mathrm{m})\end{array}$ & $\begin{array}{l}\text { Roughness } \\
(\mu \mathrm{m})\end{array}$ & $\Lambda$ \\
\hline 1350 & 2151.0 & $0.524 \times 0.572$ & 0.393 & $\begin{array}{l}R_{\mathrm{a}}=0.5 \\
R_{\mathrm{a}}=0.1\end{array}$ & $\begin{array}{l}0.556 \\
2.138\end{array}$ \\
\hline 3500 & 2954.9 & $0.719 \times 0.786$ & 0.367 & $\begin{array}{l}R_{\mathrm{a}}=0.5 \\
R_{\mathrm{a}}=0.1\end{array}$ & $\begin{array}{l}0.519 \\
1.996\end{array}$ \\
\hline 4500 & 3213.1 & $0.782 \times 0.855$ & 0.360 & $\begin{array}{l}R_{\mathrm{a}}=0.5 \\
R_{\mathrm{a}}=0.1\end{array}$ & $\begin{array}{l}0.509 \\
1.958\end{array}$ \\
\hline
\end{tabular}

centered-centroid method. For each of the six $\phi$ directions seven $\Psi$ angles (equally spaced in $\sin ^{2} \Psi$ ) were used, with an acquisition time of $50-60 \mathrm{~s}$ by peak and \pm 2 oscillations in $\Psi$. The $\mathrm{X}$-ray spot diameter was of about $1 \mathrm{~mm}$. The stresses were defined in the following way: $\sigma_{\mathrm{I}}$ as the principal circumferential stress, in the rolling direction, tangential to the rolling track and $\sigma_{\text {II }}$ for the principal axial stress, perpendicular to the rolling direction (Fig. 3a). ${ }^{20}$

For the characterization of the steel cyclic properties low-cycle fatigue tests had been carried out on a $100 \mathrm{kN}$ Dartec servo-hydraulic machine, operating at a strain rate $\dot{\varepsilon}=0.008$. The individual specimen technique for each level of strain range was used. The stable hysteresis loop was defined at $50 \%$ fatigue life of the specimen. An Instron resistance strain gauge type axial model 2620-601, with a distance between supports of $12.5 \mathrm{~mm}$ was used. These results allowed the elastoplastic constants characteristics of the material behaviour law used in the finite element model to be established. A linear kinematic hardening law has been defined from the three following parameters: elastic modulus, $E$, yield strength, $\sigma_{\mathrm{Y}}$ and kinematic hard- ening modulus, $h$. The elastoplastic constants of this law were determined by splitting the hardening cycle curve into two straights lines, one elastic and the other plastic, by using the minimum deviation square method, in which the common point was considered the yield strength. The slope of the plastic straight line was used to establish the tangent modulus, $E_{\mathrm{T}}$. The kinematic hardening modulus, $h$, was determined from the Eq. ${ }^{21}$

$\frac{1}{E_{T}}=\frac{1}{E}+\frac{1}{b}$

\section{RESULTS AND DISCUSSION}

\section{Roughness}

It is verified that after RCF tests, there are no changes in the specimens with initial surface roughness of $R_{\mathrm{a}}=$ $0.1 \mu \mathrm{m}$. On the other hand, for the specimens with $R_{\mathrm{a}}=0.5 \mu \mathrm{m}$ the surface roughness after RCF tests was $R_{\mathrm{a}}=0.16 \mu \mathrm{m}$.

The plastic deformation on the rolling track is significant and can be confirmed by the profile analysis showed in Fig. 4, where the largest width of the rolling track $(\sim 5 \mathrm{~mm})$ can also be seen.

The evolution of the surface roughness, or the lambda ratio, $\Lambda$, along a test, was measured from a RCF test at different running times. Figure 5 shows the evolution of the roughness, $R_{\mathrm{a}}$, and the lambda ratio, $\Lambda$, according to RCF test time. It is observed that there is a rapid change of the roughness (of about $30 \%$ ) just after 1 min of testing. That is to say, before the test there was a situation of faulty elastohydrodynamic lubrication, $\Lambda<1$, and after a minute a limiting condition is attained, where the size of the roughness was of the order of the lubricating oil film 


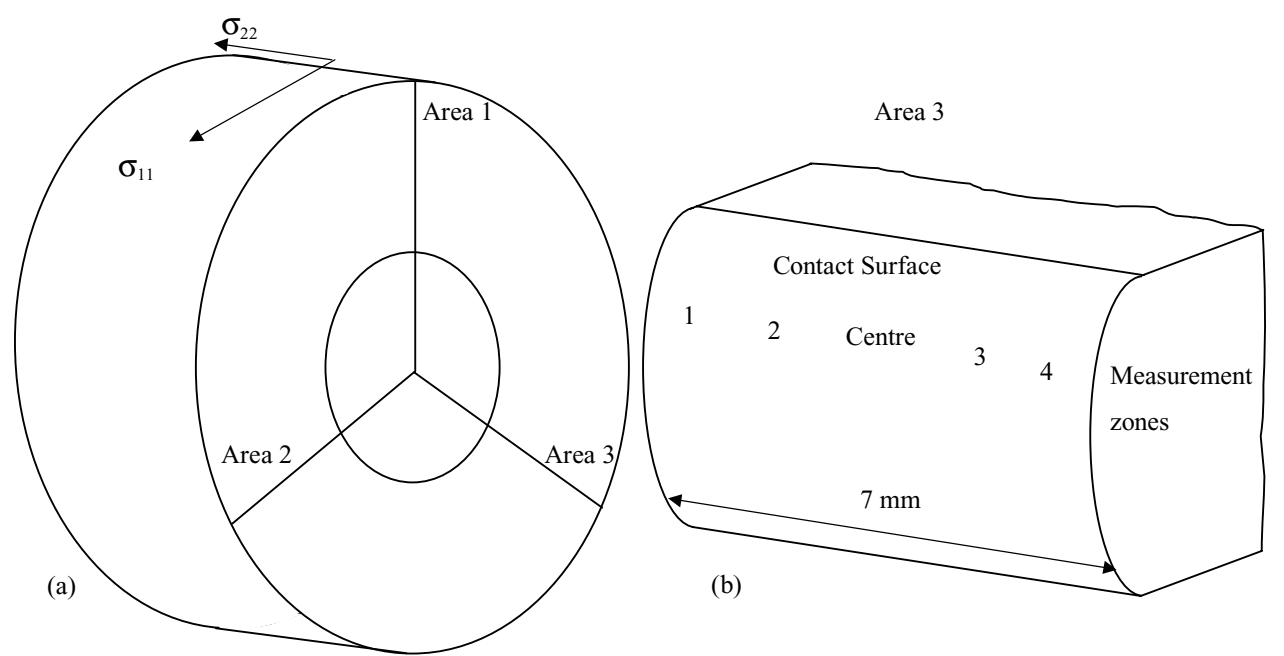

Fig. 2 (a) Measurements areas of the superficial residual stresses in the specimens; (b) measurements of the superficial residual stresses in area 3 , in several points of the width.
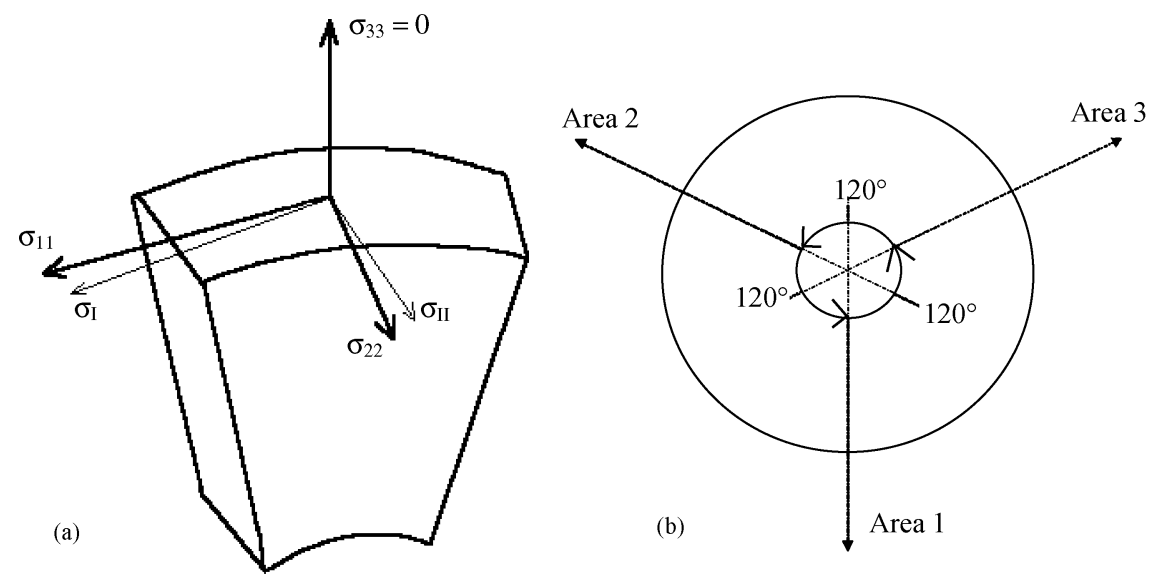

Fig. 3 (a) Reference frame of the stresses, including the principal stresses ( $\sigma_{\mathrm{I}}$ and $\left.\sigma_{\mathrm{II}}\right)$; (b) measurements areas of the residual stresses.



Fig. 4 Rolling track profile, after RCF test, where the plastic deformation can be seen $\left(\mathrm{P}_{\mathrm{H}}=3.2 \mathrm{GPa}, 1.5 \times 10^{5}\right.$ cycles). 


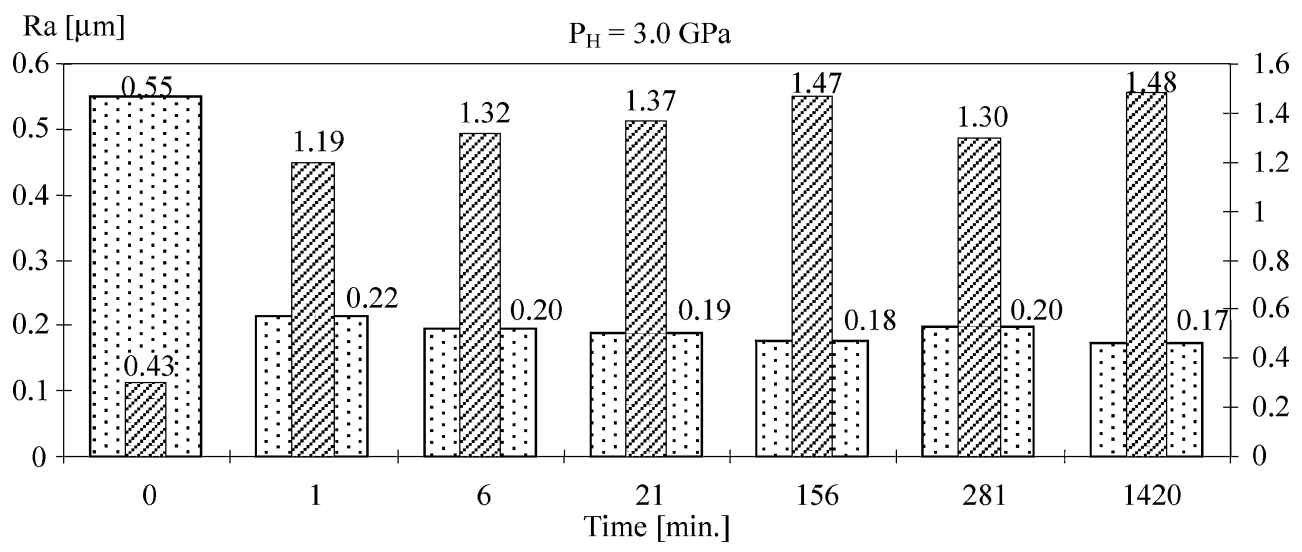

Fig. 5 Roughness, $R_{\mathrm{a}}$, and parameter, $\Lambda$, evolution in function of RCF time test for a 3.0 GPa Hertz pressure.

Table 3 Results before and after RCF test in three areas at $120^{\circ}$ (Fig. 2(a))

\begin{tabular}{llllll}
\hline & & & Area 1 & Area 2 & Area 3 \\
\hline Before & $R_{\mathrm{a}}=0.1 \mu \mathrm{m}$ & $\sigma_{11}$ & $-397 \pm 11$ & $-385 \pm 11$ & $-385 \pm 11$ \\
RCF tests & & $\sigma_{22}$ & $-576 \pm 11$ & $-562 \pm 11$ & $-560 \pm 12$ \\
& $R_{\mathrm{a}}=0.5 \mu \mathrm{m}$ & $\sigma_{11}$ & $-297 \pm 13$ & $-284 \pm 13$ & $-291 \pm 13$ \\
& & $\sigma_{22}$ & $-533 \pm 14$ & $-531 \pm 13$ & $-530 \pm 13$ \\
After & $R_{\mathrm{a}}=0.1 \mu \mathrm{m}$ & $\sigma_{11}$ & $-167 \pm 15$ & $-190 \pm 16$ & $-205 \pm 16$ \\
RCF tests & & $\sigma_{22}$ & $-72 \pm 16$ & $-154 \pm 16$ & $-150 \pm 16$ \\
& $\mathrm{R}_{\mathrm{a}}=0.5 \mu \mathrm{m}$ & $\sigma_{11}$ & $-347 \pm 15$ & $-337 \pm 15$ & $-307 \pm 15$ \\
& & $\sigma_{22}$ & $-456 \pm 16$ & $-418 \pm 16$ & $-413 \pm 16$ \\
\hline
\end{tabular}

thickness. After $5 \mathrm{~min}$ the roughness continued to decrease and, consequently, $\Lambda$ to increase. The situation stabilizes for $\Lambda$ values between 1.3 and 1.4 that corresponds to a roughness of 0.18 and 0.2 .

The initial roughness of the specimens with $R_{\mathrm{a}}=$ $0.5 \mu \mathrm{m}$, evolves very quickly after the start of the test, to a stabilized state sufficiently close to the roughness of the specimens with $R_{\mathrm{a}}=0.1 \mu \mathrm{m}$, so that the supposition of a no influence of this parameter on the lifetime can be admitted. This hypothesis is corroborated, further on, by the results of the RCF life tests.

\section{Residual stresses}

Table 3 shows the results obtained for the specimens with $R_{\mathrm{a}}=0.1 \mu \mathrm{m}$ and $R_{\mathrm{a}}=0.5 \mu \mathrm{m}$, before and after RCF tests.

It is verified that there is a good uniformity in the results obtained in the three areas, before the RCF tests. The value of residual stresses in the axial direction $\left(\sigma_{22}\right)$ is significantly higher than in the circumferential direction. As shear stresses are extremely small, they are not represented here. There was no significant scatter in the measurements made in area 3 , in several zones along the specimen width (Table 4).

Table 3 also shows the results obtained in measurements after RCF tests, in a specimens with $R_{\mathrm{a}}=0.1$ $\mu \mathrm{m}$. This specimen was tested with a Hertz pressure of $3 \mathrm{GPa}$ and had a life of 10 million cycles. It is worth pointing out the smaller compressive residual stresses obtained in the centre of the rolling track. On the contrary, (Table 4), at the extremities of the rolling track the values remained of the same magnitude as the untested specimen. This can be explained by the fact that this specimen showed a very well-marked rolling track, which is to say that it suffered strong cyclic plastic deformation (Fig. 4) inducing residual stresses relaxation.

The specimen with roughness $R_{\mathrm{a}}=0.5 \mu \mathrm{m}$ are tested under a Hertz pressure of $2.2 \mathrm{GPa}$ for a duration of $10 \mathrm{mil}-$ lion cycles. The residual stresses measured in the three zones (Table 3) reveal a relative persistence of values, as much in the circumferential direction $\left(\sigma_{11}\right)$, as in the axial direction, although in this direction they are higher. In the results obtained in the measurements across to the specimen width (Table 4) the elevated compressive residual stresses values that appear in the centre of the rolling track are highlighted, contrasting with what happened in the specimen with $R_{\mathrm{a}}=0.1 \mu \mathrm{m}$, tested with a larger Hertz pressure of $P_{\mathrm{H}}=3 \mathrm{GPa}$.

Measurements were made to obtain the residual stresses profile in the depth, before and after RCF test. The results can be seen in Fig. 6. This specimen was tested with a Hertz pressure of $2.2 \mathrm{GPa}$ and had a life of 10 millions cycles. It is verified, through this residual stresses profile analysis, made before RCF test, that the residual stresses fall quickly to zero at about $20 \mu \mathrm{m}$ depth. On the other hand, after RCF test, it is verified that there is a field of compressive residual stresses, induced by the Hertz loading, that extends to about $500 \mu \mathrm{m}$. It is observed that there is a peak of compressive stresses at about $240 \mu \mathrm{m}$ depth 
Table 4 Results before and after RCF test in area 3, in several points of the width (Fig. 2b)

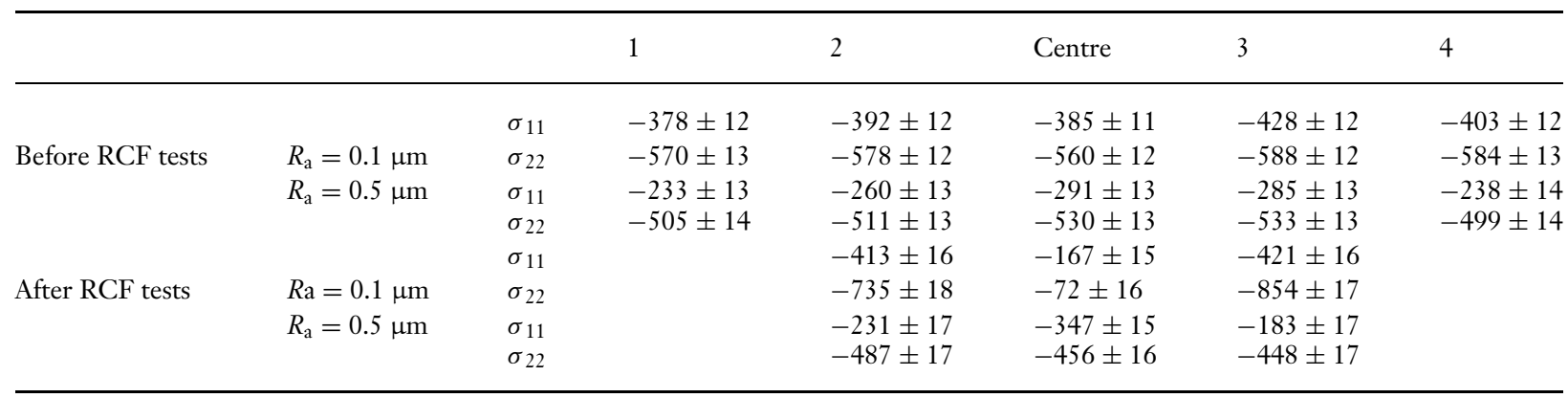
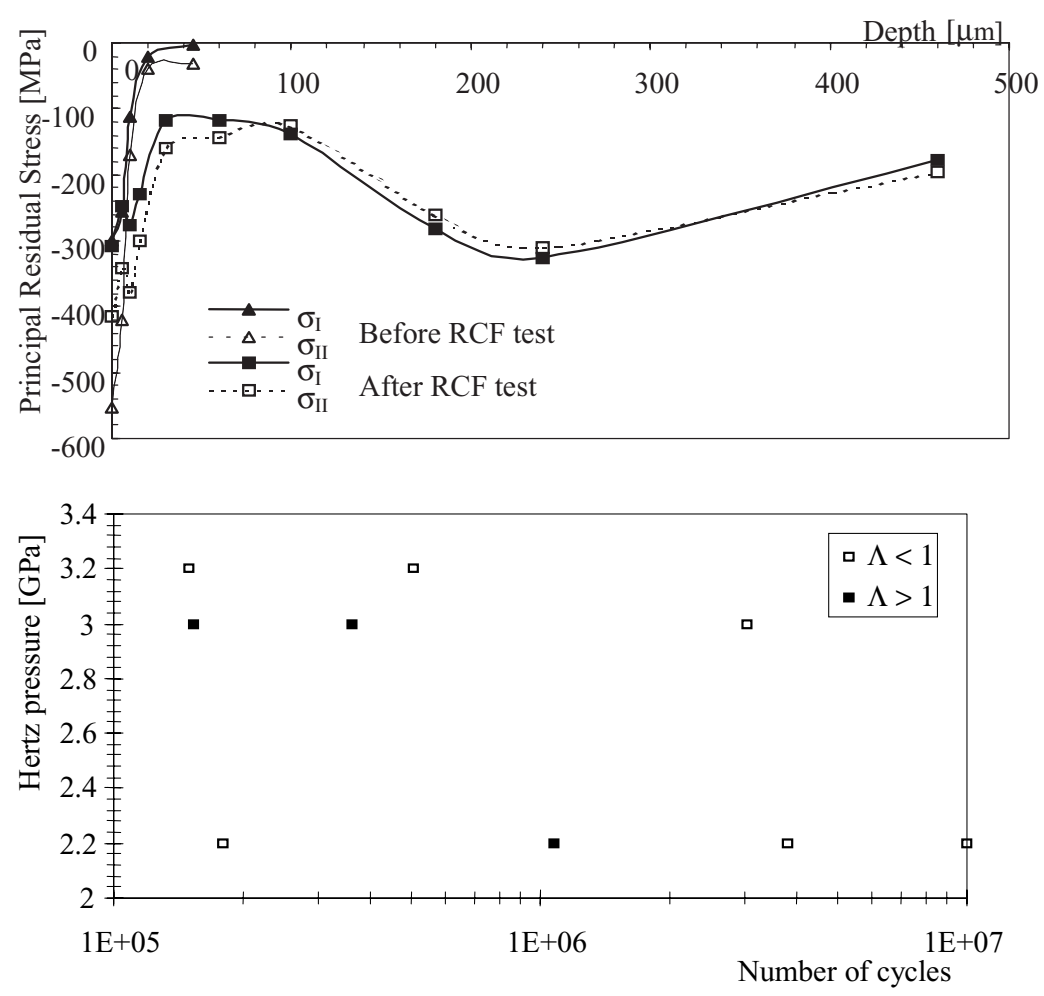

Fig. 6 Residual stress profile before and after RCF tests for the specimen with $R_{\mathrm{a}}=$ $0.5 \mathrm{~mm} ; \mathrm{P}_{\mathrm{H}}=2.2 \mathrm{GPa} ; N=10^{7}$ cycles. The deviation, $2 \sigma$, of the residual stress is of about $10 \mathrm{MPa}$.

Fig. 7 Hertz pressure-life curve in the RCF tests. that is not significantly different from the calculated by the Hertz theory: $262 \mu \mathrm{m}$.

That is to say, the initial near-surface compressive stresses due to machining are overwhelmed by cyclic plastic deformation; this phenomenon is more accentuated for more severe loadings and the elastoplastic and cyclic Hertzian loading, introduces the maximum compressive residual stresses at a depth corresponding to the maximum shear stress.

\section{Mechanisms and zones of cracking}

The results of the RCF tests can be seen in Fig. 7 in a Hertz pressure-life curve. It is not possible to observe any influence on the results of the initial surface roughness.
This is maybe because the initial roughness reduction in the first cycles of the test, as shown in Fig. 5.

On the other hand, observing the life of specimens as a function of the loading level (Fig. 7), a great dispersion of results is seen, so that there seems to be no inverse relationship between the load level and the life. It should, however, be noticed that no surface failures of the specimens were verified for Hertz pressures less than 2.2 GPa, even after more than $10^{7}$ cycles.

It was observed that the specimen life is mainly affected by the cracking morphology. Those that have a short life present a deep spall (Fig. 8a) while the others, which have a longer life, present a microspalling (Fig. 8b). This seems to indicate that if there are no superficial defects that promote spalling, the life of these specimens can be very long. Conversely, the appearance of superficial defects leads to 

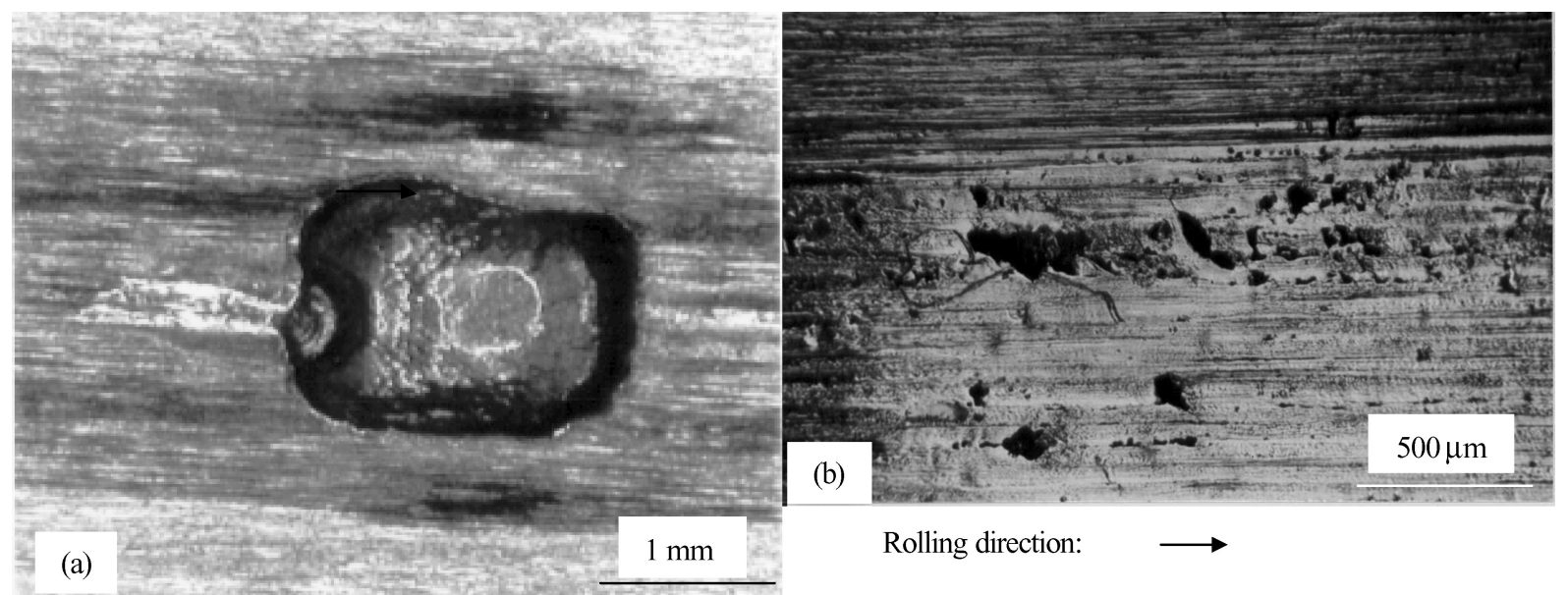

Fig. 8 Deterioration types in the specimens with $R_{\mathrm{a}}=0.5 \mathrm{~mm}$, after RCF tests: (a) Spalling $\mathrm{P}_{\mathrm{H}}=2.2 \mathrm{GPa}, N=1.8 \times 10^{5}$ cycles; and (b) Microspalling $\mathrm{P}_{\mathrm{H}}=2.2 \mathrm{GPa}, N=10^{7}$ cycles.


Fig. 9 Spalling in the specimens with $R_{\mathrm{a}}=0.5 \mathrm{~mm}$, after RCF tests: (a) $\mathrm{P}_{\mathrm{H}}=2.2 \mathrm{GPa}, N=3.78 \times 10^{6}$ cycles; and (b) $\mathrm{P}_{\mathrm{H}}=3 \mathrm{GPa}, N=3$ $\times 10^{6}$ cycles.

premature failure. The crack nucleation zone that propagates in the rolling direction, from the left to the right, can be seen in Fig. 8 a, on the left of spall. As we can see in Figs 8 and 9, the spalling can have different forms depending on the position of the superficial defects in the rolling track. In fact, it seems that, if the defect is on the centre zone of the track (Fig. 8), where the Hertz pressure is maximum, the crack rapidly reaches the critical depth and becomes uprooting. If the defects are far from the centre track (Fig. 9), the stresses are smaller, and the propagation time of the crack increases, and consequently it needs more time to reach the critical depth. That spall shows a ductile rough zone, substantially greater than in the other case.

\section{NUMERICAL SIMULATION}

\section{Description of the model}

Dang Van and Maitournam developed a systematic and efficient process for the computational analysis problems that involved loads in motion with constant velocity. This procedure avoid slow and repetitive calculations because the incremental treatment of the loading history. The algorithm used here permits one to go directly to the steadystate. This hypothesis is supported by the fact that the reference frame moves with the loading. This means that, in this reference frame, the velocity and all the physical quantities are time-independent; so, if we make a variable change, the mechanical fields are only dependent on variable $x$ (Fig. 10). That is to say, the numerical simulation is similar to an instantaneous picture of the structure that 'passes under' the load. The plastic strain state when $x$ tends towards $+\infty$ is the initial state of the structure (represented in this discretization by the most distant points located ahead of the loads); the plastic strain state at $-\infty$ (represented in this discretization by the points located far behind the loads) corresponds to the permanent residual strain after load pass (Fig. 10). Being so, in order to obtain the residual stresses and strains in the whole structure, after the loading pass, it is only necessary to make an elastoplastic calculation with the plastic deformations obtained at $x=-\infty$. 


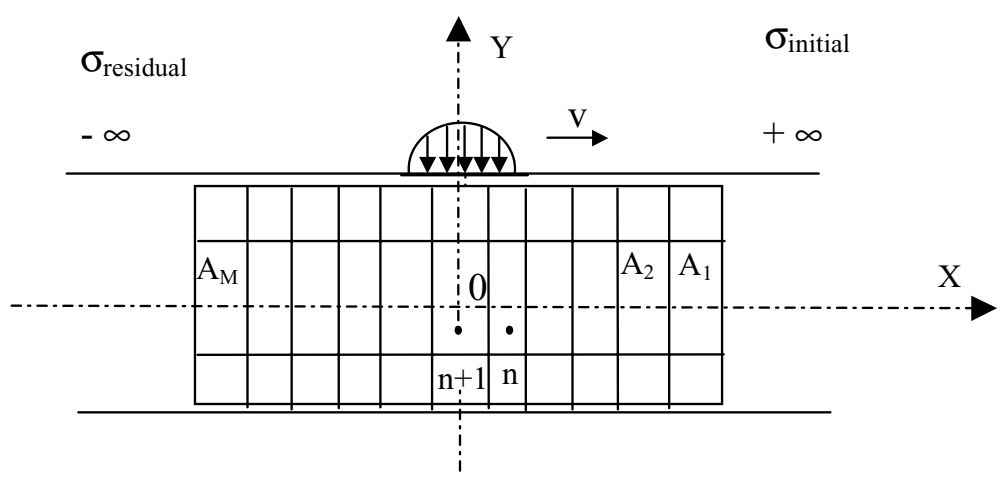

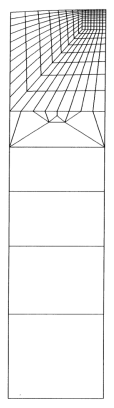

(a)

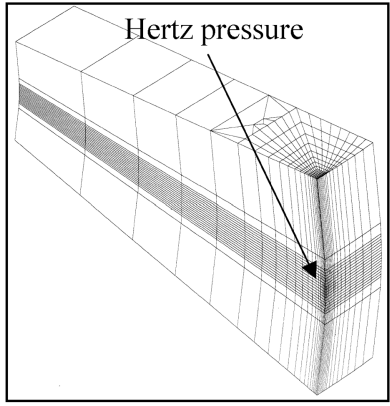

(b)

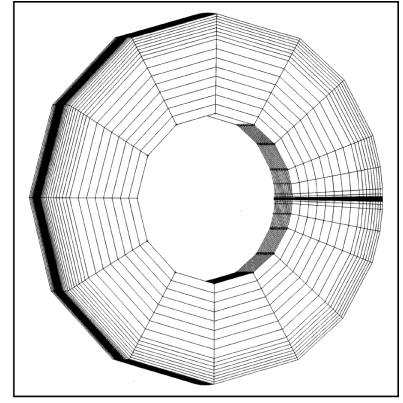

(c)
Fig. 10 Integration points of the internal variables of the steady-state method. ${ }^{23}$
Fig. 11 (a) Surface from which the mesh is generated; (b) Partial volume generated by rotating the left surface and Hertzian load; (c) Total volume generated by rotating the partial volume on the left.
To obtain the stabilized state after a finite number of passes, it is only necessary to simulate the successive passes. Each pass is made having as the initial state the residual state of the preceding passage (this is at $x=+\infty$ ). The stabilized state is attained when, at $x=\infty$, the same plastic strain is attained at $x=+\infty$. Elastic shakedown occurs if all the plastic deformation tensor components are constant, in any flow line (horizontal, in the case of Fig. 10). A plastic shakedown occurs, if at least one of these components varies between $-\infty$ and $+\infty$, and has the same value at $x=-\infty$ and at $x=+\infty$. Ratchetting occurs, if from an iteration to another, an increase in the absolute value at $x=-\infty$ arises.

The three-dimensional finite element mesh used had the real dimensions of the specimen (Fig. 11c). In order to decrease the number of elements and nodes, the mesh was symmetric in circumferential plane, i.e., half the width of the specimen. Three-dimensional rolling was achieved by rotating the model, while the semielliptical Hertzian contact distribution was maintained fixed. Figure 11a shows the surface from which the volume is generated (Fig. 11b). In this figure we can also see the Hertzian loading. This loading does not take into account the effect of the lubrication nor the effect of the surface roughness. The mesh is made up of 5400 cubic elements and 6258 nodes. On the internal diameter, the boundary conditions are restricted in the three directions of mesh displacement and symmetrical conditions in the circumferential plane are verified on the entire model.
The main file is organized as presented in the flow chart of Fig. 12.

\section{Contact conditions}

Cyclic behaviour

Low-cycle fatigue and monotonic tests gave the results shown in Fig. 13a. Throughout the strain ranges considered the material undergoes cyclic softening. The elastoplastic material behaviour (yield strength, $\sigma_{\mathrm{Y}}$, and linear kinematic hardening modulus, $b$ ) is shown in Fig. 13b. The calculations are made using data shown in Table 5. The initial residual stresses profile is shown in Table 6.

\section{Fatigue calculation}

The fatigue calculations are made using Dang Van highcycle multiaxial fatigue criterion. Taking into account the obtained results, the stresses generate, firstly, an elastoplastic loading, followed by elastic shakedown of the material.

The visualization of these results includes the identification of the elements with higher failure probability in the critical zone of the model or the direct analysis through the Dang Van diagram identifying, during the loading trajectory, the elements at risk (Fig. 14). Solving 




Fig. 12 Numerical model flow chart.

the equation of the Dang Van high-cycle multiaxial fatigue criterion

$(\forall t \in T,|\vec{\tau}(t)|+\alpha \cdot p(t) \leq \beta)$

it is possible to represent Dang Van's isocriteria in each elementary volume. That is to say, in all the elements where this equation is greater than zero they have a strong probability to suffer deterioration and they are, consequently, identified. Here, $\vec{\tau}(t)$ is the microscopic shear stress, $p(t)$ is the microscopic hydrostatic pressure, $t$ is the time and $T$ the loading cycle time. $\alpha$ and $\beta$ are material properties.
Two symmetrical straight lines in relation to the abscissa or the hydrostatic pressure axis limit the safe domain of the multiaxial fatigue criterion. These straight lines are defined by starting from two points that are obtained from classic fatigue tests: alternating torsion and alternating tension or alternating or rotating bending. For the $32 \mathrm{CrMoV} 13$ quenched and tempered steel, the classic fatigue tests values were obtained from the work of Barralis and Castex: ${ }^{22} \sigma_{\mathrm{F}}=660 \mathrm{MPa}$ and $\tau_{\mathrm{F}}=380 \mathrm{MPa}$, where $\sigma_{\mathrm{F}}$ and $\tau_{\mathrm{F}}$, are respectively, the endurance limit in rotating bending and the endurance limit in alternating torsion. 

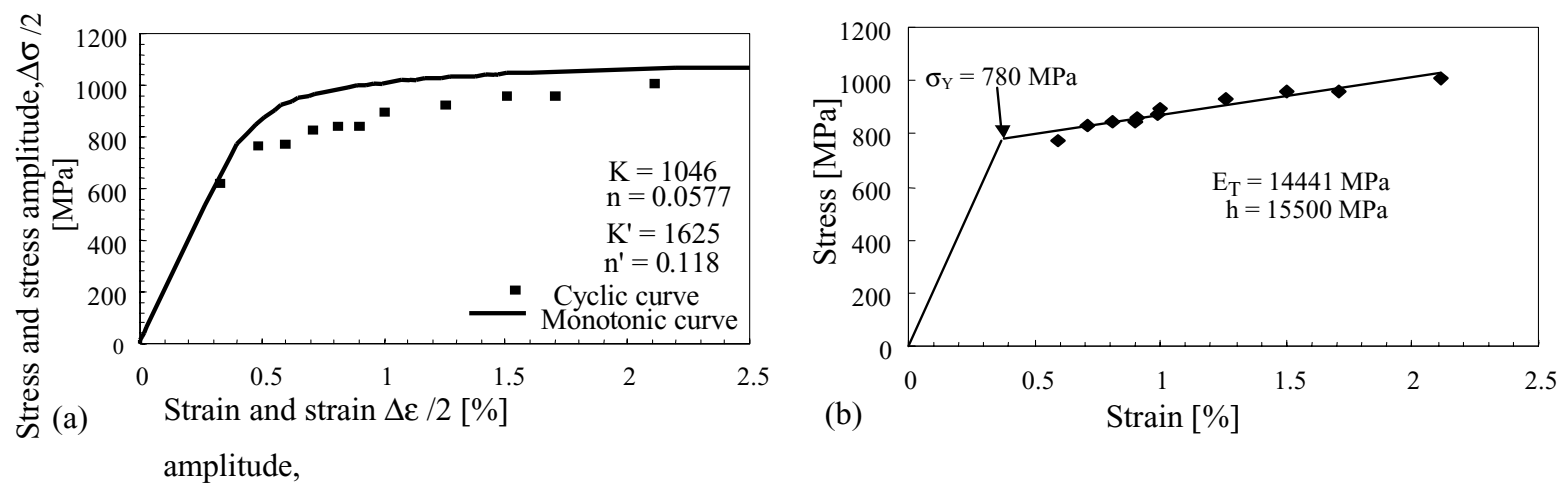

Fig. 13 (a) Monotonic and cyclic curves and hardening exponents and coefficients of each other. (b) Low-cycle fatigue tests results and linear kinematic hardening law.

Table 5 Calculation data

\begin{tabular}{|c|c|c|c|c|c|}
\hline $\begin{array}{l}\text { Load } \\
\text { (N) }\end{array}$ & $\begin{array}{l}\text { Hertz } \\
\text { pressure } \\
(\mathrm{GPa})\end{array}$ & $\begin{array}{l}\text { Elastic } \\
\text { modulus } \\
(\mathrm{GPa})\end{array}$ & $\begin{array}{l}\text { Poisson's } \\
\text { ratio }\end{array}$ & $\begin{array}{l}\text { Yield } \\
\text { strength } \\
(\mathrm{MPa})\end{array}$ & $\begin{array}{l}\text { Kinematic } \\
\text { hardening } \\
\text { modulus }(\mathrm{MPa})\end{array}$ \\
\hline 1350 & 2.2 & 210 & 0.3 & 780 & 15500 \\
\hline
\end{tabular}

Table 6 Initial residual stresses profile insert in the calculation file

\begin{tabular}{lll}
\hline $\begin{array}{l}\text { Depth } \\
(\mathrm{mm})\end{array}$ & $\begin{array}{l}\sigma_{\mathrm{r}} \text { circumferential } \\
(\mathrm{MPa})\end{array}$ & $\begin{array}{l}\sigma_{\mathrm{r}} \text { axial } \\
(\mathrm{MPa})\end{array}$ \\
\hline 0 & -300 & -553 \\
0.005 & -256 & -421 \\
0.01 & -111 & -170 \\
0.02 & -22 & -38 \\
0.045 & -3 & -31 \\
\hline
\end{tabular}

\section{RESULTS AND DISCUSSION}

In Fig. 15a we can compare the results for the initial residual stresses obtained by X-ray diffraction with those calculated with the numerical model.

Since the material was only polished, the initial residual stresses introduced have a small penetration $(50 \mu \mathrm{m})$, changing quickly from -400/-500 $\mathrm{MPa}$, to almost zero. They are more important in the axial direction $\left(\sigma_{\mathrm{II}}\right)$. In the finite element calculation we verify that the stresses have the same values in both directions. On the surface in the axial direction, the difference is significant, and the stresses have the same values after $10 \mu \mathrm{m}$ depth. The differences found in the axial direction may be related with the boundary conditions chosen for the calculation of the initial residual stress. In the circumferential direction we verify a good relationship between the stresses measured by $\mathrm{X}$-ray diffraction and the calculated ones.



Fig. 14 Dang Van high-cycle multiaxial fatigue criterion: safety domain and damaging and non-damaging loading path.

Figure $15 \mathrm{~b}$ shows the comparison between the results of the residual stresses obtained by X-ray diffraction and those calculated after Hertzian loading. We can find a good relationship between the two profiles, especially after a depth of $100 \mu \mathrm{m}$. There is also a difference between measured and calculated stresses in the axial direction, which may be due to the dimensions of the model in that direction and with the form of the loading contact area which is considered elastic and is in fact elastoplastic. Figure 16a shows the plastic deformation (including a zoom) in $x$. Vertical lines, below the rolling track, with the same values in this case, both ahead and behind the contact at a given depth, which means that elastic shakedown occurs - all the components of the plastic tensor are constants. Figure 16b shows the total deformation (including a zoom) in $y$ (with the greatest value in the depth).

All the elements that constitute the elementary volume, where the loading path exceeds the limiting line of the 


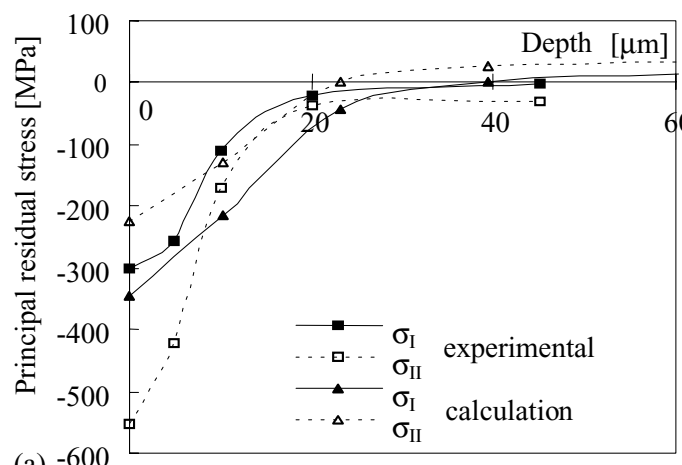

(a) -600

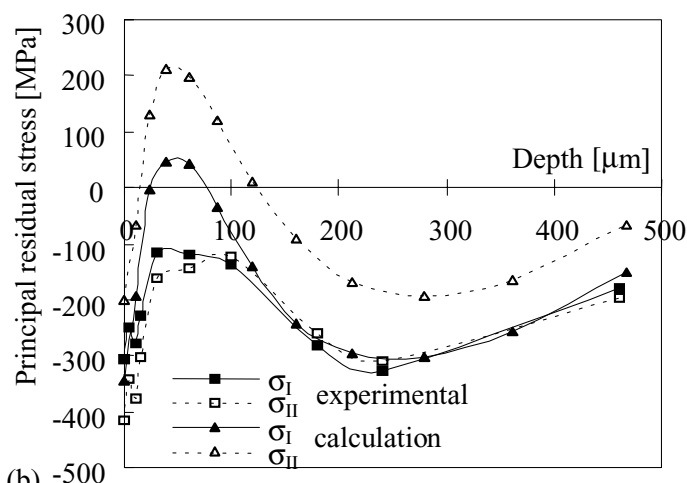

(b) -500

Fig. 15 (a) Initial residual stresses obtained by X-ray diffraction (before RCF test) and by finite element calculation. (b) Residual stresses obtained by X-ray diffraction (after RCF test) and by finite element calculation after Hertzian loading application.



Fig. 16 (a) Plastic deformation, $\varepsilon_{\mathrm{Pxx}}$. (b) Total deformation, $\varepsilon_{\mathrm{Tyy}}$.

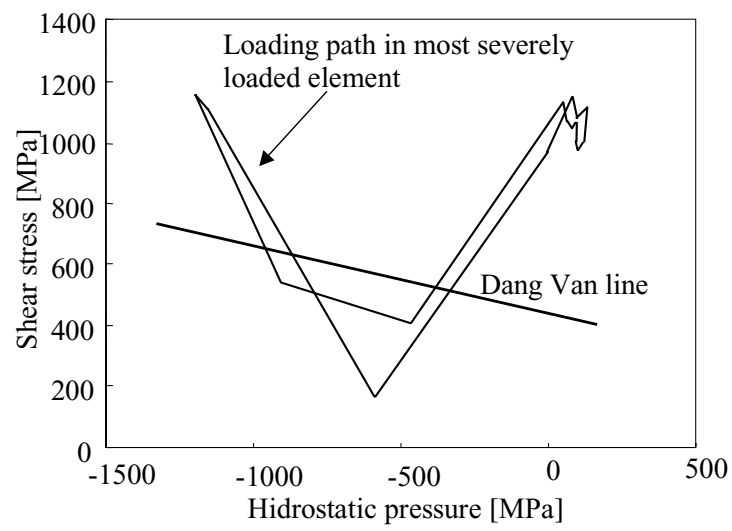

Fig. 17 Dang Van high-cycle multiaxial fatigue criterion application. Loading path in most severely loaded element.

Dang Van criterion, are identified. Figure 17 shows the loading path in the most severely loaded element.

The critical elementary volume is the one closest to the centre of the loading application. The closest cen-

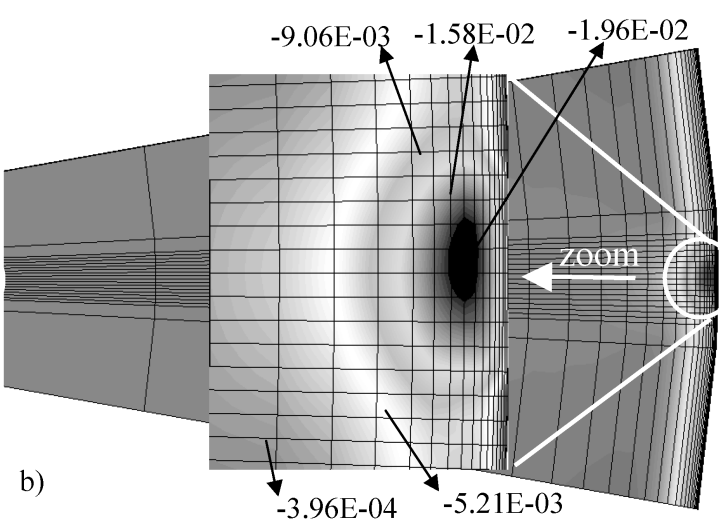

tre elementary volume is taken from the initial volume of Fig. 11b, which has the surface shape of Fig. 11a and has a very small thickness. From the calculations of the Dang Van high-cycle multiaxial fatigue criterion it is possible to determine the most probable failure zones that correspond to the elements where the loading path exceeds the limiting line of the criterion. The elementary volume with the identification at the risk zones is shown in detail in Fig. 18a. It is possible to isolate and extract from the elementary volume mesh the rupture risk elements. Figure 18c shows these elements taken from the Fig. 18a. It is verified that the damaged zone is quite big, as much in the axial direction (width) as in the radial direction (depth). The thickness of these elements corresponds to the circumferential direction. It should be noticed that due to the chosen symmetry plan, the model only represents half of the deteriorated elements. It is predicted that choosing other elementary volume close to the first one (in the circumferential direction) a similar group of damaged elements appears, although in smaller numbers since it is away from the loading centre. Making the same 


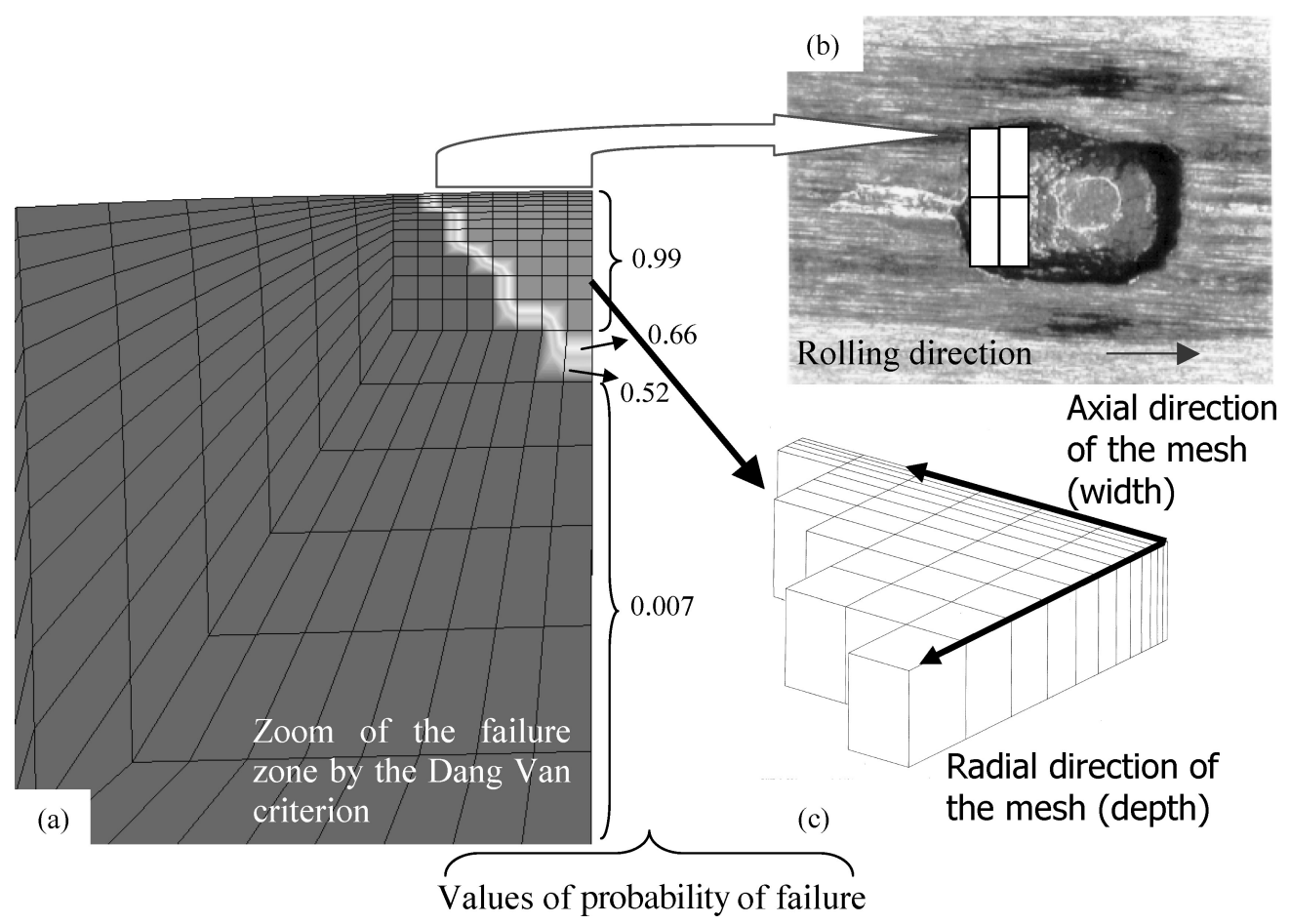

Fig. 18 Elements with the highest probability of failure by the Dang Van high-cycle multiaxial fatigue criterion.

reasoning for all the elementary volumes that constitute the initial volume it would be expected that the identified risk zone would have a close configuration of the typical spalling found in this material Fig. 18b.

\section{CONCLUSIONS}

Pure RCF experiments were conducted in $32 \mathrm{CrMoV} 13$ quenched and tempered steel. The influence of roughness and residual stresses on the mechanisms and zones of cracking were studied. The following conclusions are made.

The results show a rapid decrease in roughness during the first minute of test but even so there will be deterioration of the specimens; consequently, there are no differences in terms of Hertz pressure-life curve for the two levels of roughness.

The compressive residual stress state induced by the Hertz loading, to a considerable depth, stands out from the analysis of the in-depth residual stresses profile. After RCF tests the largest value appears at a depth corresponding to that where the maximum shear stress occurs. On the other hand, a change in the residual stresses is verified in the surface, due to elastoplastic cyclic loading.

A three-dimensional finite elements model to describe the elastoplastic behaviour of this material using a linear kinematic hardening law was developed. This model allows the introduction of an initial residual stress state and is able to simulate the frictionless and no lubrication rolling contact. We can point out: The initial residual stresses profile calculated is closed to the one measured experimentally.

The circumferential residual stresses profile calculated after Hertzian loading is similar to the one measured by $\mathrm{X}$-ray diffraction, starting at $100 \mu \mathrm{m}$ depth, beyond the influence of roughness, which is not included in the model.

The axial residual stresses profile calculated has a difference of $|100| \mathrm{MPa}$ from the one measured experimentally because of the specimen width dimension and the form of the loading contact area.

The application of the Dang Van high-cycle multiaxial fatigue criterion revealed the most probable locations for the failure zones.

\section{REFERENCES}

1 Tallian, T. E. (1992) Failure Atlas for Hertz Contact Machine Elements. ASME, New York, USA.

2 Voskamp, A. P. (1985) Material response to rolling contact loading. Trans. ASME, 7. Tribol. 107, 359-336.

3 Syniuta, W. D. and Corrow, C. J. (1970) A scanning electron microscope fractographic study of rolling-Contact fatigue. Wear 15, 187-199.

4 Clarke, T. M., Miller, G. R., Keer, L. M. and Cheng, H. S. (1985) The role of near-surface inclusions in the pitting of gears. ASLE Trans. 28, 111-116.

5 Lund, T. (1996) Elaboration d'un acier à roulement de qualité. Evolution 1, 23-26. 
6 Ichimaru, K., Nakajima, A. and Hirano, F. (1981) Effect of asperity interaction on pitting in rollers and gears. Trans. ASME, 7. Mech. Des. 103, 482-491.

7 Cheng, W., Cheng, H. S. and Keer, L. M. (1994) Longitudinal crack initiation under pure rolling contact fatigue. Trib. Trans. $37,51-58$.

8 Soda, N. and Yamamoto, T. (1982) Effect of tangential traction and roughness on crack initiation/propagation during rolling contact. ASLE Trans. 25, 198-206.

9 Muro, H., Tsushima, T. and Nagafuchi, M. (1975) Initiation and propagation of surface cracks in rolling fatigue of high hardness steel. Wear 35, 261-282.

10 Zaretsky, E. V., Parker, R. J. and Anderson, W. J. (1969) A study of residual stress induced during rolling. Trans. ASME, 7. Lubr. Technol. 2, 314-319.

11 Bhargava, V., Hahn, G. T. and Rubin, C. A. (1985) An elastic-plastic finite element model of rolling contact. Part 1: Analysis of single contacts, Part 2: Analysis of repeated contacts. Trans. ASME, 7. Appl. Mech. 52, 67-82.

12 Hahn, G. T., Bhargava, V., Rubin, C. A., Chen, Q. and Kim, K. (1987) Analysis of the rolling contact residual stresses and cyclic plastic deformation of SAE 52100 steel ball bearings. Trans. ASME, 7. Tribol. 109, 618-626.

13 Batista, A. C., Dias, A. M., Lebrun, J. L., Le Flour, J. C. and Inglebert, G. (2000) Contact fatigue of automotive gears: Evolution and effects of residual stresses introduced by surface treatments. Fatigue Fract. Engng Mater. Struct. 23, 217-228.

14 Kulkarni, S. M., Hahn, G. T., Rubin, C. A. and Bhargava, V. (1991) Elasto-plastic finite element analysis of repeated three-dimensional, elliptical rolling contact with rail wheel properties. Trans. ASME, 7. Tribol. 113, 434-441.
15 Dang Van, K. and Maitournam, M. H. (1993) Steady-state flow in classical elastoplasticity: Applications to repeated rolling and sliding contact. 7. Mech. Phys. Solids 41, 1691-1710.

16 Dang Van, K. (1993) Macro-micro approach in high-cycle multiaxial fatigue. Advances in Multiaxial Fatigue, ASTM STP 1191 (Edited by D. L. McDowell and R. Ellis), American Society for Testing Materials, Philadelphia, pp. 120-130.

17 Vergne, P. and Flamand, L. (1995) La lubrification elastohydrodynamique. Etat actuel des recherches. $L a$ Lubrification des Engrenages. Recueil de Conférences - CETIM, $1-23$.

18 Dowson, D. (1995) Elastohydrodynamic and micro-elastohydrodynamic lubrication. Wear 190 $125-138$.

19 Hamrock, B. J. and Dowson, D. (1977) Isothermal elastohydrodynamic lubrication of point contacts: Part III-Fully flooded results. Trans ASME, 7. Lubr. Technol. vol. 99, 264-276.

20 Batista, A. C. and Dias, A. M. (2000) Characterization of mechanical properties in surface-treated materials. F. Test. Eval. 28, 217.

21 Lemaittre, J. and Chaboche, J.-L. (1996) Mécanique des matériaux solides. Edition Dunod, Paris.

22 Barralis, J. and Castex, L. (1986) Improvement of rotative bending and rolling contact fatigue of nitrided 32CDV13. Residual Stresses in Science and Technology — Garmish Partenkirrchen Vol. 2, 679-686.

23 Hanus, E., Maitournam, H. and Dang Van, K. (1996) Pressure rolling contact: Steady state flow analysis and comparison with experimental data. Int. 7. Solids Struct. 33, $3739-3753$ 